Edith Cowan University

Research Online

Research outputs 2014 to 2021

$9-15-2022$

\title{
Navigating the territories of transition: An exploration of the experiences of transnational social workers in Aotearoa New Zealand
}

Shajimon Peter

Edith Cowan University

Liz Beddoe

Allen Bartley

Follow this and additional works at: https://ro.ecu.edu.au/ecuworkspost2013

Part of the Arts and Humanities Commons, Business Commons, and the Social and Behavioral Sciences Commons

$10.1177 / 0020872820956261$

This is an author's accepted manuscript of: Peter, S., Beddoe, L., \& Bartley, A. (2022). Navigating the territories of transition: An exploration of the experiences of transnational social workers in Aotearoa New Zealand. International Social Work, 65(5) 856-869. SAGE. https://doi.org/10.1177/0020872820956261

This Journal Article is posted at Research Online.

https://ro.ecu.edu.au/ecuworkspost2013/9538 
Now published as:

Peter, S., Beddoe, L., \& Bartley, A. (2020). Navigating the territories of transition: An exploration of the experiences of transnational social workers in Aotearoa New Zealand. International Social Work, doi:10.1177/0020872820956261

\title{
Navigating the territories of transition: An exploration of the experiences of transnational social workers in Aotearoa New Zealand
}

\author{
Shajimon Peter, Liz Beddoe and Allen Bartley
}

\begin{abstract}
This qualitative study conducted three focus groups with transnational social workers (TSWs) in three cities of Aotearoa New Zealand. The aim of the study was to examine the transitional experience of TSWs, particularly in relation to any strategies and mechanisms existing in the host country to facilitate their personal and professional transition. A significant finding is that a coherent profession-wide programme for facilitating the transition is absent as the existing practices are mostly within the employer-employee relationships. Transitional experiences of TSWs are explained using the metaphor of 'territory' and some strategies for effective transition are suggested.
\end{abstract}

Key Words: Transnational social workers, focus groups, professional transition, personal transition

\section{Introduction}

Social workers relocate to other countries to undertake professional practice and this phenomenon has recently become more common among the Anglophone countries, as some existing studies have demonstrated (Bartley \& Beddoe, 2018; Beddoe, Fouché, Bartley, \& Harington, 2012; Brown, Sansfaçon, Éthier, \& Fulton, 2014; Hanna \& Lyons, 2016; Hussein, 2018; Modderman, Threlkeld, \& McPherson, 2018). One of the reasons for this growth is that countries like the UK, Australia, New Zealand, and Canada have a shared tradition of recruiting overseas educated social workers to fill their labour shortages (Modderman, Threlkeld, \& McPherson, 2017). Increasing global mobility of other professionals such as nurses and 
teachers and their transition into receiving countries have been well reported (Chun Tie, Birks, \& Francis, 2018; Peter, Bartley, \& Beddoe, 2019).

A study conducted in New Zealand found that in 2010 transnational social workers formed nearly $10 \%$ of the registered workforce (Bartley, Beddoe, Duke, Fouché, Harington, \& Shah, 2011). Although no current data is available, there is no reason to believe that this number has reduced given the significant presence of TSWs in the social work field. It is predicted that a growing segment of the workforce will include those who have been educated in another country (Bartley \& Beddoe, 2018).

Relocating to another country offers short or long-term employment opportunities and is a reasonable risk that migrating social workers often take. A significant aspect contributing to the risk is the experience of a "professional dislocation" resulting in a "profound, lasting sense of unease linked to disjuncture between the practice environment on the one hand, and their perceptions of the status of the profession and their own professional identity" (Fouché, Beddoe, Bartley, \& de Haan, 2013a, p. 2006). Such similar experience, including meeting racism and discrimination has been reported in research conducted ten years ago by Fouché, Beddoe, Bartley, and Benton (2013b) and later by Hatzidimitriadou and Psoinos (2017). The cultural dimension of relocating to a very different society is a frequent source of both anxiety and great learning, somewhat dependent on the nature of the welcome (Fouché, Beddoe, Bartley, \& Parkes, 2015; Walsh-Tapiata, Simmons, Meo-Sewabu, \& Umugwaneza, 2018). While transition programmes might potentially ameliorate this experience, there are none in New Zealand currently except employer-led ad hoc arrangements (Beddoe \& Bartley, 2018), despite the model proposed by Walsh-Tapiata et al. (2018) for Māori cultural practices such as Pōwhiri to provide a welcome and support for transition. In the continuing absence of a coherent approach to supporting the transition of TSWs, what is the prevailing situation? How do TSWs navigate their transition and what do they experience in terms of their professional and personal transition? This article attempts to answer these questions.

The research team consisted of three researchers - two who had previously conducted research in this field of inquiry and a researcher who is a TSW himself. The study began with an extensive thematic literature review that examined existing transition programmes for nurses, teachers, and social workers (Peter et al., 2019). It was found that while nurses and teachers receive some form of induction programmes to facilitate their transition into the receiving 
countries, no known coherent strategies were located for facilitating the transition of transnational social workers. The review identified a significant gap in knowledge, where research exploring understanding of TSWs' subjective perceptions of their professional transition is scarce. The current study aims to address this gap and has employed a qualitative approach in order to gain a deeper account of the experiences of TSWs. Transition is both personally and professionally complex and is rarely supported by a planned and systematic programme.

\section{Conceptual Clarifications}

A transnational social worker (TSW) is defined as one "who undertakes professional practice in any other country than [their] home country or the one in which [they] received [their] training and qualification" (Peter et al., 2019, p. 17).

In this study 'professional transition' is defined as the process in which professionally qualified social workers relocate from a country to another for professional practice. It involves learning to practice confidently and competently in the host country by meeting the necessary requirements, which may include qualification recognition, registration with regulatory bodies or membership with professional associations as set by the host country (Papadopoulos, 2016; Fouché et al., 2013b). 'Personal transition' refers to the social, emotional, psychological and spiritual processes of learning to adapt to the new environment individually or as a family. This is the 'settling in' experience in which the newly arrived professionals negotiate their social lives. Our study describes the complexity and intertwined nature of these transitions. Possession of various forms of capital (Bourdieu, 1984) eases the way through the transition phase but also their lack poses barriers to settling in.

\section{Methodology}

Data were collected via focus groups with TSWs. Unlike face-to-face individual interviews, focus groups allow for "joint construction of meaning" (Bryman, 2016, p. 501) by the participants on a given topic about which they have a shared understanding and experience. Three focus groups with TSWs were conducted in 2017 in three New Zealand cities. An invitation to participate in the study was sent out by the Social Workers Registration Board (SWRB). This strategy was an efficient way to reach out to all TSWs who have been registered with the SWRB and were practicing in New Zealand. In addition, some regional managers of 
larger organisations offered assistance to recruit TSWs. In one instance, a generous regional manager invited the researchers to speak to her local managers and team leaders when they gathered for a routine meeting. A total of $20 \mathrm{TSWs}$ participated in the study - six each participated in two cities and eight participated in the third location. The country of origin of participants included the UK, South Africa, India, Spain and the Philippines although a significant majority were from the UK, particularly England.

Ethical approval was obtained from the University of Auckland Human Participants Ethics Committee and a major employing organisation in New Zealand, Oranga Tamariki-Ministry for Children (statutory child welfare).

Each focus group took approximately two hours and all were audio-recorded and transcribed. In order to encourage active participation of members, prompts were given on the topics of personal transition, settling in, and professional transition. This produced enthusiastic open discussions as the participants passionately explored and interpreted their experiences. The study provided an opportunity for TSWs to come together to discuss their experience and perspectives, and some travelled long distances to participate in the study.

The qualitative data analysis software NVivo was used to aid coding and the development of themes. The analysis of the transcripts involved a two-layered, iterative approach. Initially, a simple analysis of the responses to the topic prompts was employed in order to describe what relocating to a new country entailed for TSWs. Second, a thematic analysis examined critical themes that linked TSWs' personal and professional transition to the broader socio-cultural and social work professional narratives of New Zealand (Terry, Hayfield, Clarke \& Braun, 2017). These narratives were organised in a way that explored how they impede or promote TSWs' transition to the receiving country. The findings reported below developed from these two layers of analysis. Recurrent themes developed in this process include the challenges of arrival, navigating the personal transition, settling in, and navigating the professional transition, which are explained using 'territory' as a metaphor for the navigation of these complex processes.

\section{Findings: Territory as a metaphor}

Territory provides a useful metaphor to capture the complexities and challenges experienced both personally and professionally by TSWs. Territories are both literal and metaphorical in this context as they include the new locations, systems, process and structures with which 
TSWs interact as they negotiate their transition. Within these locations and structures both opportunities and constraints are encountered and these were mediated by forms of social capital (Bourdieu, 1984) and relations of power (Evans \& Sinclair, 2016). Foucault (1981) states, "Power is not something that is acquired, seized or shared, something one holds on to or allows to slip away" (p. 94). Rather power is relational as it becomes apparent only when it is exercised within social relations. Because power is relational, it is embedded in processes, procedures and practices which people encounter (Townley, 1993). Thus, the societal, cultural and structural processes and procedures encountered by TSWs entering the profession in New Zealand are imbued with power relations which are seen to be either promoting or impeding their transitions.

The metaphor of territory also relates to the jurisdictions within which TSWs navigate their transition. The etymological root of the term territory takes us to the Latin word 'terra' meaning land and 'territorium a place from which people are warned [off]" (Delaney, 2005, p. 14, citing the Oxford English Dictionary). Parallels can be found in the present-day concept of the nation (welfare) state that has historically been "premised on the defence of entitlements and privileges to those who are presumed citizens" (Hugman, Moosa-Mitha, \& Moyo, 2010, p. 630). There are many forms of social work and while there may some commonly held values and ethical principles, there are also significant differences (Ornellas et al., 2018). Irrespective of whether regulated or not, the social work profession has country-specific requirements that relocating professionals must adhere to. These elements include forms of social and cultural capital: proficiency in language, cultural competency, recognition of qualifications and membership or registration with professional associations or bodies. On entering new territory TSWs must navigate complex tensions, opportunities and possibilities, and negotiate systems along the way in a journey that is both geographical and socio-cultural. Analysis of the data has identified three territories that relate to TSWs transitional experience that are delineated below.

\section{Territory 1: 'Arrival' and securing employment}

The first territory involves TSWs navigating the vagaries of relocation and employment. Hugman et al. (2010) argue that the migration of social workers can be interpreted as transformative or transgressive with associated implications such as exercise of their social citizenship. They point out that social workers migrate as a result of direct recruitment to meet 
market needs of the host country or as a result of personal social and economic desires such as seeking a better quality of life. Focus group discussion of participants provided some evidence that direct recruitment and networking privileges enabled some participants to successfully manage arrival and employment while challenges and hardships were faced by those who lacked such privilege and faced discrimination. An Indian TSW who migrated with the hope of getting a social work job found lack of knowledge of local transport, securing a rented accommodation, and landing a job most challenging: "You won't believe me, from morning till evening I used to walk" (Participant 6). She reported that she could not rent a house because the real estate agents doubted her ability to pay for rent without a job.

\section{Employment difficulties}

A major difference in experience between social workers from the global north as opposed to the global south was direct recruitment. No TSWs from the global south reported direct recruitment. They undertook other easily available lower-paid less skilled jobs before being recruited for a proper social work job. However, surprisingly no participants explicitly related this to discrimination or made reference to racism. Working as support workers or care-giving in residential care homes were experiences shared by two Indian and two Filipino TSWs. A senior TSW from the UK worked as a customs officer before obtaining a social work job while another UK TSW worked with a childcare agency as a nanny.

By comparison, TSWs who came through direct recruitment found their arrival and employment a smoother affair. "I had one day off from my work and just fired off loads of applications ... and then [one was successful]. It was as simple as that really, yeah, it wasn't too complicated" (Participant 12 UK). Possessing cultural capital (for example, strong English, professional credentials and experience) and having social capital (family or professional connections in the host country) provided significant facilitating factors at the arrival stage. Participant 8 (UK) applied for jobs in cities where she had family and friend connections. Participant 9 (UK) applied for jobs before visiting a friend in New Zealand and the visit allowed her to attend an interview which helped her obtain a social work job at a hospital. Participant 1 (UK) visited her daughter during holidays which became a "fact-finding mission to look for jobs" because her daughter suggested her to relocate. She was able to secure a social work job three months after. Participant 14 (UK) said that friends assisted her to send out her resume through a network that allowed her to learn of a social work job vacancy and apply for the post. 
Traversing the territory of arrival and securing employment included two significant facilitating factors for TSWs: direct recruitment and TSWs' own cultural and social capital (education and professional credentials and helpful connections). Absence of these led to impediments in transition including an unreceptive employment market and challenges in negotiating the initial settling in. Although market needs acted as a causal factor for crossborder practice, this did not manifest favourably for those who migrated through other means than direct recruitment, despite social work jobs being readily available in the host country.

\section{Territory 2: 'Settling in' -personal transition}

Navigating personal transition involves emotional, cultural, social and financial concerns for TSWs. Often, concurrent negotiation of both personal and professional transition is necessitated by their arrival and employment situation in the host country. These become barriers to their transition.

\section{Personal struggles}

The challenges to settling in may be experienced in both personal and professional realmspersonal and family struggles occur contemporaneously with professional challenges. In the case of Participant 5, a TSW who migrated from the Philippines with her husband and two children, English language skills and accents provided a major challenge. She revealed that the struggle was not just for herself but for her children too:

My children struggle a lot. It is easy for my youngest to learn because she can adapt the accent, but with my [teenager] until now she feels isolated and she doesn't relate well to others and she experiences a lot of bullying at school" (Participant 5).

This participant's account reveals that the initial phase of migration was extremely challenging emotionally and financially because it was the first time she travelled outside the Philippines and many aspects of life were very different and often alarming. Initial employment opportunities or their lack in the host country can throw challenges that relocating professionals fail to envisage:

When my husband found a job [in New Zealand] we had to move to the place where he worked. We did not know where to catch a bus and when we moved into a house, we didn't know how safe it was and it turned out that some drug addicts stayed there in a separate room and it was really traumatic. It really traumatised me because when we stayed in the place, we didn't know anybody and then they made 
some noise that we did not understand ... they were laughing, drinking ... We moved from one place to another... four months, four houses (Participant 5).

Migrant practitioners sometimes find that their own experience of hardship in the newly arrived country can make them feel helpless to manage their own affairs:

You feel like you are on another planet. The language is new, the culture is new, and I felt so dumb myself. I was very competent as I was a manager back in the Philippines and when I came in here, I felt so dumb that nobody knows me (Participant 5).

The challenges of transition impacted on family finances as well. Another TSW (Participant 6, Philippines) who came to New Zealand with her husband, leaving behind her children, found a job in a major city, but she found it extremely hard to feel settled when her husband worked away in another New Zealand city with children remaining in the Philippines. The family had to pay rent for two properties and had to send money back home to support their children. Negotiating visas and the right to work is another challenge that affects TSWs emotionally and financially. As mentioned earlier, agency recruitment, support from family and friends, and personal professional networks featured as mitigating factors. TSWs who relocated to New Zealand with a work visa through direct overseas recruitment faced fewer challenges in settling in while those who migrated using any other visas had a range of challenges to face before securing their first recognised social work job. Those who belonged to the latter often had to do other work before getting a proper social work post.

\section{Territory 3: 'Navigating the professional context' - professional transition}

The major focus of our study was the professional transition of TSWs, although we note that personal and professional transitions were often interwoven. Analysis of focus groups revealed that TSWs negotiated a range of challenges to traverse this territory. A significant challenge TSWs face relates to their experience of substantial difference in the professional practice.

Professional dislocation: Understanding the professional and cultural context

As noted in previous research, this is a major challenge as TSWs report lasting feelings of 'professional dislocation' (Fouché et al., 2013a) and may experience racism (Fouché et al., 2013b). In the absence of carefully planned transition programmes, transition often becomes a journey of trial and error for TSWs. The participants described several significant areas of 
learning including the legal dimensions of practice, difference in the nature of work and differences in the scope of practice and related roles of social workers, especially in multidisciplinary teams. These are explained below.

Reflecting earlier studies (Fouché et al., 2013a) Participant 2 (UK) found that social work is very different in the new country, which she did not expect having imagined that the New Zealand professional environment would not be that different to home. She felt that she had to learn to slow down because in the UK social work was fast paced. She observed that learning to slow down in her role as a professional practitioner was the biggest cultural surprise for her initially. A TSW (Participant 1, South Africa), who worked as a family therapist in her home country, moved to New Zealand to work in a hospital setting. She narrated her experience of working in the emergency department, where she attempted to use her family therapy skills to work with a woman who presented with domestic violence, “... I called a family meeting because I'm a family therapist and in ED that didn't work, but I didn't know that".

One TSW who worked in statutory child protection highlighted important differences in such practice in the UK and in New Zealand. Matters of law and practice posed a challenge to familiar ways of working with children at risk. In her UK experience, common practices enabled social workers to "override guardianship to remove a child deemed at risk, because child protection comes first". Her impression of practice in New Zealand was difficult to understand because of the complex legal requirements for family consultation (Participant, 16 UK).

Another TSW (UK) who practices in the mental health setting experienced inflexibility in budgets in New Zealand in comparison to the more flexible and service-specification led contracting available in the UK. Consequently, she found it difficult to engage in conversations about service funding for supportive living (Participant, 15). In mental health an experienced TSW (UK) observed that she is not deemed to be qualified to assess people's mental capacity in New Zealand, although she made such assessments about six times a day in the UK. This has led her to feel confused about her social work role in New Zealand. This experience confirms what Fouché et al. (2013) described as the 'enduring professional dislocation' discussed above, where practitioners do not feel they are fully using their skills and that they don't fit in to this territory. 
UK educated social workers working in multidisciplinary teams in hospital settings in New Zealand experienced professional dislocation more strongly than those in other fields, where social work was the main profession. Participant 7 (UK) felt that medical professionals 'hijack social work' in the New Zealand context. Another hospital-based TSW who discussed her experience of multidisciplinary team meetings remarked that social workers merely arranged the meeting and after that they would sit and take notes because they were not really wanted there for their professional input (Participant, 9, UK). In a similar vein, Participant 8 talked about the fast-paced discharge plan social workers have to work out in New Zealand. She remarked that her opinions and skills are often not recognised by other members in the multidisciplinary team. She added that it took a while to regain confidence in her ability, and the initial transitional phase was hard to face:

For the first few [cases], you are literally scrambling around, which is a horrible feeling to have when you come from feeling quite confident in your role ... here it's like I don't know my job, I don't know anything, back to square one, back to basics (Participant 8).

Culturally competent work in New Zealand involves understanding the Maori concept of whanau (family) that refers to the collective responsibility family members have towards the wellbeing of children (Ruwhiu, 2013). Within this understanding, consulting the whanau is an essential aspect that newly arriving TSWs are often unaware of. Understanding the differences between individualist and collectivist practice approaches are important while working with indigenous communities within the bicultural context of New Zealand (Eketone \& Walker, 2015).

Social work in New Zealand has a unique bicultural practice context based on the Treaty of Waitangi that put in place a partnership between Māori and the British Crown (Eketone \& Walker, 2015). TSWs had very little knowledge of the bicultural practice prior to their arrival in New Zealand. A UK educated social worker acknowledged that she had underestimated the significance of the bicultural aspect of New Zealand social work practice (Participant 18, UK). While she was familiar with multicultural context of social work practice in the UK, the bicultural practice context was something she found very challenging. The "biggest shock" for her was that there was nothing available online to learn about bicultural practice other than the opportunity to learn Māori language. A similar view was expressed by a TSW from another European country. Bicultural practice was difficult because it was unknown before relocating 
(Participant, 17 Spain). One TSW (UK) revealed that she gained some understanding of bicultural practice during workplace induction but applying that to practice was totally different, and she felt she had to learn a great deal more to feel confident. The lack of a clear understanding of the significance of The Treaty of Waitangi in underpinning bicultural practice led to one TSW arguing that multiculturalism is more inclusive and that New Zealand "needs to go beyond bicultural practice" (Participant, 20).

Negotiating registration

Negotiating social work registration is a significant aspect of the professional transition of TSWs. Employers recruited TSWs even if they did not have a registration at the time of recruitment, provided that TSWs agreed to process their registration within a stipulated time. The registration process involves the assessment of qualifications and assessment of required competencies. While Australian Association of Social Work accredited social work qualifications are accepted, other applicants whose qualifications are gained outside New Zealand must have these recognised through formal application processes (SWRB, 2019). The more cumbersome process TSWs experienced, however, was the assessment of competencies for registration as it involved explanations with evidence of a range of demonstrated competencies (SWRB, 2019).

As noted above competency to work with Māori people is a major requirement in New Zealand. Absence of facilitative strategies and mechanisms to educate TSWS on socio-cultural and professional aspects of this competency coupled with inadequate knowledge of the competency requirements made TSWs feel overwhelmed when faced with SWRB registration. Cultural attunement to work with Māori is in the regulatory legislation in New Zealand thus its necessity may be experienced as a bureaucratic rather than professional proficiency requirement. This was particularly highlighted in one focus group. They used expressions like "disappointment" (Participant 14), "loose and broad [criteria]" (Participant, 17), "onerous process" (participant 18), "shocking and cumbersome process" (Participant $15 \mathrm{UK}$ ), and "strange process" (Participant 13). A misgiving about the competency assessment was clear from the comment that "it just asked stuff that you kind of think, do I have to prove myself" (Participant 17). 
Ensuring competency of the workforce to engage in professional practice is extremely important and the efforts regulatory or other bodies make in this regard cannot be undermined. SWRB has been doing a commendable job in this regard. However, most countries have robust qualifying programmes of study that provides trainees with necessary skills and knowledge. This was a point of argument for a senior TSW who claimed that her training in the UK was "so robust and extreme" alongside mandatory registration that she found the assessment process more like a scrutiny of her work, “...it doesn't give you the sense that you are a professional" (Participant 13, UK).

Lack of empathic understanding from the employers can create particular challenge to TSWS. Participant 9 (UK) found it hard to engage in her social work practice while at the same time processing her competency assessment. Participant 12 (UK) pointed out the difficulty arising from employing agency demanding registration within a given timeframe. This made her feel very much stressed as her manager grew impatient when the registration did not come through.

\section{Transition support}

Amongst the factors that TSWs identified as significantly facilitating transition was support. A TSW (UK) commented, "It is important that you found somebody who is on that journey with you almost, and you can kind of have conversations with, when you are having a bad day it does help" (Participant 12). Participant 5 (Philippines) was highly appreciative of the support she received in the form of peer supervision in her agency for an hour every week. Realising the value of the support from people with similar experience as her, she on her own initiative developed an e-mail networking with all the social workers of her ethnicity for sharing information and gaining support in times of need.

While the support of experienced TSWs is invaluable during the transitional phase, their availability was an issue in some organisations. In those situations, TSWs found peer support of experienced team members very useful. A TSW (Participant 9, UK) remarked, "It would be like well you can go out with that social worker today and you co-work a case together because in that way you can learn from them, and it was really good because you got to see other people's practice. However, where there are no arranged mechanisms for peer support, TSWs have the challenging task of obtaining required information from willing colleagues, about 
which Participant 12 lamented, "Some have offered more information than others, some will tell you if you ask them".

While some TSWs reported very diverse experiences of induction programmes being offered by employing organisations some others reported that they received none. Two UK TSWs who migrated to work in the health sector in two different regions had differing experiences in terms of induction. One received some form of induction while the other did not. The one who did not receive any induction commented, "There was nothing, absolutely nothing, which makes me absolutely adamant that there should be an induction" (Participant 1). Another social worker spoke about working in two different branches of the same organisation. She revealed that she did not receive any induction at all in one branch but received a year-long online induction in another branch when she joined there. A senior TSW who works as part of a multidisciplinary team emphasised the support she witnessed her newly recruited nursing colleagues receiving on arrival in comparison to little support she herself received:

We've recruited three British nurses ... the support to these new [nurses] has been incredible, but that is the way it should be. They are nurses and the professional transition is difficult for them. I was on call with one of them this weekend and she was saying how welcoming it's been ... So, it must be teams that are used to recruiting from overseas put that extra effort ... it is how it should be when you come a long way (Participant, 15).

When induction was offered to TSWs, the nature of the programme varied across organisations. Participant 5 commented that in the agency where she first worked, they offered the same form of induction to TSWs and newly qualified locally educated social workers. Participant 16 remarked that she and her colleague received a basic induction that included "how to evacuate the hospital in case of fire". Participant 11 spoke about one organisation that provided external professional supervision when she had requested more help during her transition, "You can go out and get professional supervision outside of the organisation. They actually pay for it".

Orientation to the bicultural approach to practice was highlighted by several participants as being highly variable and thus a crucial weakness both in the initial arrival phase, and further on, as discussed in more detail below. Participant 9 commented that she did not receive any induction for a month when she took up a social work role and orientation towards Māori cultural practices commenced after another two or three months. Participant 10 who worked in different branches of an organisation asserted that manager's support played a significant role in receiving a good induction. In some places the induction was limited to help to learn a waiata 
(song in the Māori language) while in another place she was encouraged to learn basic Māori language. She added, "You really do have to get the support of your employer and if they support those programmes, it will happen" (Participant 10). This sentiment was shared by Participant 19 (UK) who expressed disappointment about not being able to find a programme of transition that enabled learning on bicultural social work practice. Participant 13 (UK) who has been working in a social work team that consistently recruited TSWs revealed, "If you think about how many people from overseas are coming [here], it is interesting to see there is not a lot of structure and processes to facilitate that process [of transition]". What surprised the researchers was that these TSWs included practitioners and managers in a team that has been recruiting TSWs for quite a long while now and yet there was still no coherent mechanism established for facilitating the transition of newcomers.

Participants proposed solutions

TSWs discussed various forms of programmes such as bridging programmes, peer support, mentoring for assisting transition, however, a consensus was in favour of a generic online programme that provides training on socio-cultural, historical, professional and policy contexts of the host country. Participants generally agreed that the responsibility for orientation needs to be taken away from the employers because they were sceptical about the intentions of the employers. They made a clear distinction between a generic orientation to social work in New Zealand and specific job-related induction.

I think it [orientation] should be taken out of the employer's face because they have another objective. The objective is for you to do the work. It is not about how difficult it is for you to get your head around it. I think that getting your head around it is what needs to be done (Participant 13)

...people come as individuals and so how would you set up some transition that is not within the job they are going to be doing, because if you come to a job then your transition is going to be focused on that (Participant 30).

Participant 24 suggested that while in-service induction could be offered by employers, a generic transition programme could be offered by other bodies such as universities.

\section{Discussion}

Analysis suggests that a coherent strategy for facilitating the transition of TSWs is non-existent currently. Rather, there are either diverse ad hoc induction/orientation transition programmes 
with varying goals, duration and quality provided by the managers of some organisations or none at all. This finding is consistent with the thematic literature review, which examined existing transition programmes for facilitating the transition of transnational teachers, nurses and social workers among the Anglophone countries (Peter et al.,2019). While nursing and teaching provide some form of profession-wide or system-wide strategies for transition, social work is limited to the narrow bounds of the employer-employee relationship.

Whereas professional transition under the current circumstances generated comparable challenges to TSWs in general, personal transition led to varied experiences. As regards professional transition, lack of familiarity with the local policy and legal contexts, being uninformed about bicultural practice, perceived differences in professional practice in comparison to home country, feeling of prior skills being overlooked or disregarded by employers and a perceived expectation by the employer that TSWs know their job and will get on with it on their own are all common experience of TSWs on the whole. Personal transition, however, produced differing experiences. Direct recruitment by employers, having a relative or friend in the host country or having some form of connections or networking with someone in the host country and having financial backup were factors that made personal transition relatively smooth and straightforward for some TSWs. These factors enabled TSWs to address their social, emotional, and financial needs without much ado. However, absence of these made personal transition a disempowering experience for others as some had to engage in less skilled jobs prior to obtaining their social work job while others had to encounter financial hardships. Some other TSWs had to endure prolonged family separation that caused emotional and psychological stress.

TSWs navigate their professional transition depending on a range of factors including the type of agency they join, the knowledge and willingness of managers to provide relevant transition programmes, availability of supportive and helpful team members, and the kind of job they are involved with. SWRB registration that required TSWs to demonstrate a range of relevant competencies engendered particular challenges owing to the lengthy and cumbersome process involved. It seems that an assumption that their cultural capital (in this case professional education and credentials) will enable them to relocate relatively easily. The expression of frustration, particularly by those who came from jurisdictions where social work is a regulated profession, suggest that this in not at all a helpful assumption. Participants frustrations echo those of social workers in Australia (Papadopoulos, 2016) and Canada (Brown et al., 2014). 
These findings suggest that an assumption may be held both by TSWs and employers and professional bodies in host countries that Anglophone countries are assumed to have broadly comparable social work practice. While efforts may be made to pursue mutual agreements on the transference of registration with regulatory bodies or membership with professional associations (see SWRB, 2019) these arrangements alone may be insufficient to ease the transition of professionals.

At present, the burden of navigating the professional and personal transition is explicitly on the TSWs. The TSWs in this study reported that the lack of systematic transition support creates avoidable stress, disempowerment and 'professional dislocation'. Leaving the responsibility to facilitate the transition of TSWs to the employment relationship is inadequate as it gives rise to a range of disjointed efforts that are unrelated and unregulated, and which do not fully meet their needs. While this is a small study, its findings echo those found in other jurisdictions (Brown et al., 2014; Papadopoulos, 2016) and we recommend further exploration of formal structured programmes. Nurses in Australia, for example, were found to report better adjustment when offered additional supports (Chun Tie et al., 2018). While migration includes some personal challenges beyond the scope of professional bodies, the intersections between personal and professional transition suggests that better professional support might ease the relocation experience as a whole.

\section{Conclusions and recommendations}

As the global definition of social work highlights, the profession promotes social change, social cohesion and empowerment of people based on the principles of social justice, human rights, collective responsibility and respect for diversity (IFSW, 2019). This definition by virtue of its identification of 'collective responsibility' and 'respect for diversity' offers social work professional bodies opportunities to intervene to facilitate TSWs' transition.

All the same, it is important to ensure that transitional programmes are not based on a deficit focused approach of what TSWs lack. TSWs relocate to another country with the possession of a range of strengths including professional knowledge, skills, practice experience and an openness and willingness to adapt to the new professional and social contexts of their arrival country. However, the new environment of the host country brings a new set of initial challenges that not all TSWs are adequately prepared to face. 
A new collaborative partnership between professional bodies, employers and TSWs could identify and address transitional needs. A strengths-based collaborative approach might avoid top-down and one-size-fits-all programmes, cautioned against in other professions such as teaching (see McCluskey, Sim, \& Johnson, 2011). For example, the historical, legal and policy context of social work in New Zealand, its unique bicultural practice were aspects that challenged TSWs at the initial phase of their transition. As suggested by the research participants, a national generic programme could be established to provide transition education on legislation, policy and the socio-cultural context of social work in New Zealand as these were common aspects of relocation challenges encountered by all the TSWs. TSWs arrive with certain expectations based on their social work education and practice experience, which needs an appropriate forum for expression and clarification. A structured transition programme can adequately and meaningfully prepare the TSWs for professional practice by allowing them opportunities for clarifying expectations from both employers and TSWs themselves.

The social work profession has respect for diversity and views it as a strength rather than something to be feared. Arrival of TSWs adds more richness to the diversity and additionally brings in ready-to-use knowledge and skills to join the local workforce. Taking a collective responsibility to acknowledge both the potential contribution and the challenges and assist via a structured programme of transition presents an effective strategy to be developed through a participatory and collaborative approach involving various stake holders including professional bodies, TSWs and their employers and schools of social work.

Note: The study was carried out at the University of Auckland in New Zealand. The first author is now Edith Cowan University in Western Australia.

\section{REFERENCES}

AASW \& SWRB (2016) 'Information sheet for social workers: Mutual recognition agreement (MRA) between Australian Association of Social Workers (AASW) and New Zealand Social Workers Registration Board (SWRB)'. Accessed on 30 January 2020 from https://www.aasw.asn.au/document/item/5767

Bartley, A. \& Beddoe, L. (2018) Transnational social work: Opportunities and challenges of a global profession. Bristol, UK: Policy Press.

Bartley, A., Beddoe, L., Duke, J., Fouché, C., Harington, P. R. J., \& Shah, R. (2011) 'Crossing borders: Key features of migrant social workers in New Zealand'. Aotearoa New Zealand Social Work, 23(3), 16-30. 
Beddoe, L., \& Bartley, A. (2019) 'Reviewing the benefits and challenges of overseas practice: Reflections upon coming home'. Aotearoa New Zealand Social Work, 31 (1), 72-88.

Beddoe, L., Fouché, C., Bartley, A., \& Harington, P. (2012) 'Migrant social workers' experience in New Zealand: Education and supervision issues. Social Work Education, 31(8), 1012-1031.

Bourdieu, P. (1984) Distinction: A social critique of the judgement of taste, translated by R. Nice. London: Routledge \& Kegan Paul.

Brown, M., Sansfacon, A. P., Ethier, S., \& Fulton, A. (2014) 'A complicated welcome: Social workers navigate policy, organizational contexts and socio-cultural dynamics following migration to Canada'. International Journal of Science Studies, 3(1), 58-68.

Bryman, A. (2016) Social research methods (5 ${ }^{\text {th }}$ Edition). Oxford, England: Oxford University Press.

Chun Tie, Y., Birks, M., \& Francis, K. (2018) 'Playing the game: A grounded theory of the integration of international nurses'. Collegian. doi:10.1016/j.colegn.2018.12.006

Delaney, D. (2005). Territory: A short introduction. Malden: Blackwell Publishing.

Eketone, A., \& Walker, S. (2015) 'Bicultural practice: Beyond mere tokenism'. In K. van Heugten \& A. Gibbs (Eds.), Social work for sociologists: Theory and practice (pp. 103119). New York NY Palgrave Macmillan

Evans, M. M., \& Sinclair, A. (2016) 'Navigating the territories of indigenous leadership: Exploring the experiences and practices of Australian Indigenous arts leaders'. Leadership, 12(4), 470-490. doi: 10.1177/1742715015574318.

Fouché, C., Beddoe, L., Bartley, A., \& de Haan, I. (2013a) 'Enduring professional dislocation: Migrant social workers' perceptions of their professional roles'. British Journal of Social Work, 44(7), 2004-2022. doi:10.1093/bjsw/bct054

Fouché, C., Beddoe, L., Bartley, A., \& Brenton, N. (2013b) 'Strengths and struggles: Overseas qualified social workers' experiences in Aotearoa New Zealand'. Australian Social Work, 67(4), 551-566. doi:10.1080/0312407x.2013.783604

Fouché, C., Beddoe, L., Bartley, A., \& Parkes, E. (2015) 'Are we ready for them? Overseasqualified social workers' professional cultural transition'. European Journal of Social Work, 19(1), 106-119. doi:10.1080/13691457.2015.1022858

Foucault, M. (1981). The history of sexuality: Vol. 1. The will to knowledge. London: Penguin.

Hanna, S., \& Lyons, K. (2016) ' London calling': The experiences of international social work recruits working in London'. British Journal of Social Work, 47(3), 719-736. Doi: 10.1093/bjsw/bcw027.

Hatzidimitriadou, E., \& Psoinos, M. (2017) 'A qualitative analysis of migrant social workers' work experiences and perceived prejudice from an empowering acculturative integration approach'. European Journal of Social Work, 22(3), 472-484. doi:10.1080/13691457.2017.1366299 
Hugman, R., Moosa-Mitha, M., \& Moyo, O. (2010) 'Towards a borderless social work: Reconsidering notions of international social work'. International Social Work, 53(5), 629-643. doi: 10.1177/0020872810371203

Hussein, S. (2018) 'Inter-European social workers' mobility within a dynamic social work and immigration policy context: a case study of England'. European Journal of Social Work, 1-14. doi:10.1080/13691457.2018.1539836

IFSW. (2019) 'Global definition of social work'. Accessed on 31 August 2019 from https://www.ifsw.org/what-is-social-work/global-definition-of-social-work/

McCluskey, K., Sim, C., \& Johnson, G. (2011) 'Imagining a profession: A beginning teacher's story of isolation'. Teaching Education, 22(1), 79-90.

Modderman, C., Threlkeld, G., \& McPherson, L. (2017) 'Transnational social workers in statutory child welfare: A scoping review'. Children and Youth Services Review, 81, 21-28.

Modderman, C., Threlkeld, G., \& McPherson, L. (2018) 'Transnational social workers' lived experience in statutory child protection'. European Journal of Social Work. Published online on 31 August 2018. Doi: 10.1080/13691457.2018.1517114

Ornellas, A., Spolander, G., Engelbrecht, L. K., Sicora, A., Pervova, I., Martínez-Román, M.A., . . . Strydom, M. (2018) 'Mapping social work across 10 countries: Structure, intervention, identity and challenges'. International Social Work, 62(4), 1183-1197. doi:10.1177/0020872818788395

Papadopoulos, A. (2016) 'Migrating qualifications: The ethics of recognition'. British Journal of Social Work, 47(1), 219-237. doi:10.1093/bjsw/bcw038

Peter, S., Bartley, A., \& Beddoe, E. (2019) 'Transnational social workers' transition into receiving countries: What lessons can be learned from nursing and teaching?' European Journal of Social Work, 22(1), 16-29. doi: 10.1080/13691457.2017.1366430.

Ruwhiu, L. A. (2013) 'Making sense of indigenous issues in Aotearoa New Zealand', In M. Connolly \& L. Harms (Eds.), Social Work: Contexts and practice (3rd ed., pp. 124137). Melbourne Oxford.

SWRB. (2019) Overseas qualifications. Accessed on 31 August 2019 from https://swrb.govt.nz/for-social-workers/overseas-qualified-social-workers/

Terry, G., Hayfield, N., Clarke, V., \& Braun, V. (2017). Thematic Analysis. In C. Willig \& W. S. Rogers (Eds.), The SAGE Handbook of Qualitative Research in Psychology (pp. 1736). London: SAGE

Townley, B. (1993) 'Foucault, power/knowledge, and its relevance for human resources management'. The Academic of Management Review, 18(3), 518-545.

Walsh-Tapiata, W., Simmons, H., Meo-Sewabu, L., \& Umugwaneza, A. (2018) 'Pōwhiri: A safe space of cultural encounter to assist transnational social workers in the profession in Aotearoa New Zealand'. In A. Bartley \& L. Beddoe (Eds.), Transnational social 
work: Challenges and opportunities of a global profession. (pp. 155-170) Bristol, UK: Policy Press. 